\title{
New Methods for Personal Exposure Monitoring for Airborne Particles
}

\author{
Kirsten A. Koehler ${ }^{1}$ • Thomas M. Peters ${ }^{2}$
}

Published online: 18 September 2015

(C) Springer International Publishing AG 2015

\begin{abstract}
Airborne particles have been associated with a range of adverse cardiopulmonary outcomes, which has driven its monitoring at stationary central sites throughout the world. Individual exposures, however, can differ substantially from concentrations measured at central sites due to spatial variability across a region and sources unique to the individual, such as cooking or cleaning in homes, traffic emissions during commutes, and widely varying sources encountered at work. Personal monitoring with small, battery-powered instruments enables the measurement of an individual's exposure as they go about their daily activities. Personal monitoring can substantially reduce exposure misclassification and improve the power to detect relationships between particulate pollution and adverse health outcomes. By partitioning exposures to known locations and sources, it may be possible to account for variable toxicity of different sources. This review outlines recent advances in the field of personal exposure assessment for particulate pollution. Advances in battery technology have improved the feasibility of 24-h monitoring, providing the ability to more completely attribute exposures to microenvironment (e.g., work, home, commute). New metrics to evaluate the relationship between particulate matter and health are also being considered, including particle number concentration, particle composition measures, and particle
\end{abstract}

This article is part of the Topical Collection on Air Pollution and Health

Kirsten A. Koehler

Kirsten.koehler@jhu.edu

Thomas M. Peters

thomas-m-peters@uiowa.edu

1 Department of Environmental Health Science, Johns Hopkins University, 601 N Wolfe St, Baltimore, MD 21205, USA

2 Department of Occupational and Environmental Health, University of Iowa, 145 N Riverside Dr, Iowa City, IA 52242, USA oxidative load. Such metrics provide opportunities to develop more precise associations between airborne particles and health and may provide opportunities for more effective regulations.

Keywords Exposure $\cdot$ Particulate matter $\cdot$ Personal monitoring $\cdot$ Sensor technology

\section{Introduction}

Particulate matter (PM) air pollution ranks as one of the leading causes of morbidity and mortality worldwide [1]. This high burden of disease reflects a range of adverse cardiopulmonary health effects that have been associated with air pollution exposures $[2,3]$ and the fact that exposure to air pollution is involuntary - we must breathe where we are, regardless of the air quality. Currently in the USA, the Environmental Protection Agency (EPA) requires states to monitor the mass concentration of ambient PM smaller than $2.5 \mu \mathrm{m}\left(\mathrm{PM}_{2.5}\right)$ and smaller than $10 \mu \mathrm{m}\left(\mathrm{PM}_{10}\right)$ at stationary, central locations, sometimes called area measurements. Measured concentrations are to be maintained below the National Ambient Air Quality Standards (24 h and annual averages for $\mathrm{PM}_{2.5}$; and $24 \mathrm{~h}$ for $\mathrm{PM}_{10}$ ) to protect public health. A wealth of information has been gathered showing consistent associations among ambient air quality and many adverse health outcomes [4, 5]. Such associations are important because air quality regulations are currently limited to ambient air quality—regulations have not been implemented indoors, even for public spaces. Recent studies have shown that even at concentrations below current EPA regulations, health effects persist [6, 7]. It is important to recognize, however, that studies of ambient air quality and health outcomes very likely underestimate the true relationship between PM and health because the 
epidemiological studies that rely on area measurements from central ambient air quality monitors to assign personal exposures are subject to exposure misclassification [8]. Exposure misclassification results from high levels of within-individual and between-individual variability in PM introduced by the fact that people are mobile, visiting multiple microenvironments daily (e.g., home, work, school, transit, eateries, etc.), spending a majority of their time indoors [9], and conducting activities that produce PM in their vicinity (the "personal cloud"). Moreover, PM can vary across a region, meaning that area concentrations measured at a central location may not be representative of exposures in any of these environments where individuals spend their time.

Personal monitoring was pioneered in occupational studies to better characterize exposures of individual workers. In 1960, Sherwood and Greenhalgh [10] introduced the first small battery-operated pump and air sampling device designed to directly measure personal exposure, a substantial improvement over taking a single area sample to assess exposure. Within a decade, personal sampling came to dominate industrial hygiene as the primary form of assessing exposures [11]. In early studies characterizing personal exposures to PM, cumulative samples were collected on filter media using simple air sampling inlets that were intended to capture "total dust" or "total suspended particulate". Recognizing the wide range of particle sizes relevant to human health (spanning three to four orders of magnitude in particle diameter), sizeselective sampling was initiated in the 1970s. The occupational and environmental communities have taken different paths for size-selective particulate sampling. By the late 1990s, the industrial hygiene community had reached general consensus to assess PM exposures using samplers that reflect physiological penetration into different regions of the respiratory tract (inhalable, thoracic, and respirable fractions) [11]. In contrast, regulators of ambient air pollution (i.e., EPA) designated sizebased metrics $\left(\mathrm{PM}_{10}\right.$ and $\left.\mathrm{PM}_{2.5}\right)$ based partially on health, but also on the sources of pollution that contributed to PM in each size range. Due to the different sampling strategies, exposure assessment has been predominantly siloed into occupational and environmental categories, rarely capturing a more holistic view of exposures in all microenvironments.

More recently, improvements in personal sampling pumps, sensor technology, and battery technology have enabled researchers to investigate personal exposure to a variety of environmental pollutants beyond cumulative particulate or gas sampling. Direct-reading instruments (DRIs) incorporate sensors that provide a "real time" indication of contaminant concentrations, allowing simultaneous high temporal and spatial resolution measures of various contaminants when carried by an individual along their daily route. This review will outline the latest developments in cumulative and direct-reading instruments for personal exposure assessment of particulate air pollutants. A brief description of the operating principle, advantages, and disadvantages are compiled in Table 1. We will not go into great detail on the use of instruments that have been commonly used for personal exposure assessment for more than 5 years. The review will conclude with measurement of important covariates and some remaining challenges for studies deploying personal exposure assessment.

\section{Approaches for Estimating PM Mass}

\section{Size-Selective Methods for Cumulative Mass}

Personal size selective samplers have long been used to collect particles for subsequent gravimetric or chemical analysis. We review these methods briefly here because they remain the most commonly used way to assess personal exposure to PM. Most size-selective samplers remove particles larger than a certain size with a cyclone or impactor and then collect smaller particles onto a filter. A suite of samplers, called personal environmental monitors (PEMs, MSP Corporation), rely on an impactor jet to collect larger particles onto an oilsoaked, sintered metal plate with collection efficiency characterized by the diameter of the particle associated with $50 \%$ collection, the cutoff diameter, $d_{50}$. PEMs are available with various cutoff diameter $(2.5$ and $10 \mu \mathrm{m})$ flow rates $(2,4$, and $10 \mathrm{~L} \mathrm{~min}^{-1}$ ). These cutoff diameters are consistent with the EPA National Ambient Air Quality Standards for $\mathrm{PM}_{2.5}$ and $\mathrm{PM}_{10}$. PEMs have been used extensively in environmental research, such as the study of adverse health effects from exposure to secondhand tobacco smoke [65] and the study of particulate triggers on asthma [66].

Other size-selective samplers collect particles according to inhalable, thoracic, or respirable conventions [67]. These conventions are based on how particles interact with the human respiratory tract with shallow collection efficiencies compared to $\mathrm{PM}_{2.5}$ and $\mathrm{PM}_{10}$ [68]. Inhalable samplers are used for substances that are hazardous if deposited anywhere in the respiratory tract, collecting only those particles that can enter the respiratory system via the nose and mouth $\left(d_{50}=100 \mu \mathrm{m}\right)$. These collection characteristics are achieved with a mouthlike opening (IOM, SKC Inc.) or a perforated curved surface inlet (Button Aerosol Sampler, SKC Inc.). Thoracic samplers are used for substances that are hazardous when deposited in the lung airways and gas-exchange region $\left(d_{50}=10 \mu \mathrm{m}\right)$. A parallel particle impactor (SKC Inc.) has been used to achieve these collection characteristics. Respirable samplers typically employ a cyclone inlet (e.g., Respirable Dust Aluminum Cyclone, SKC Inc.) to remove large particles $\left(d_{50}=4 \mu \mathrm{m}\right)$ with a filter to collect the smaller particles that can pass into the gasexchange region. These samplers are used primarily in occupational settings.

Recent advances in size-selective samplers have sought to improve limits of detection for inhalable sampling and 

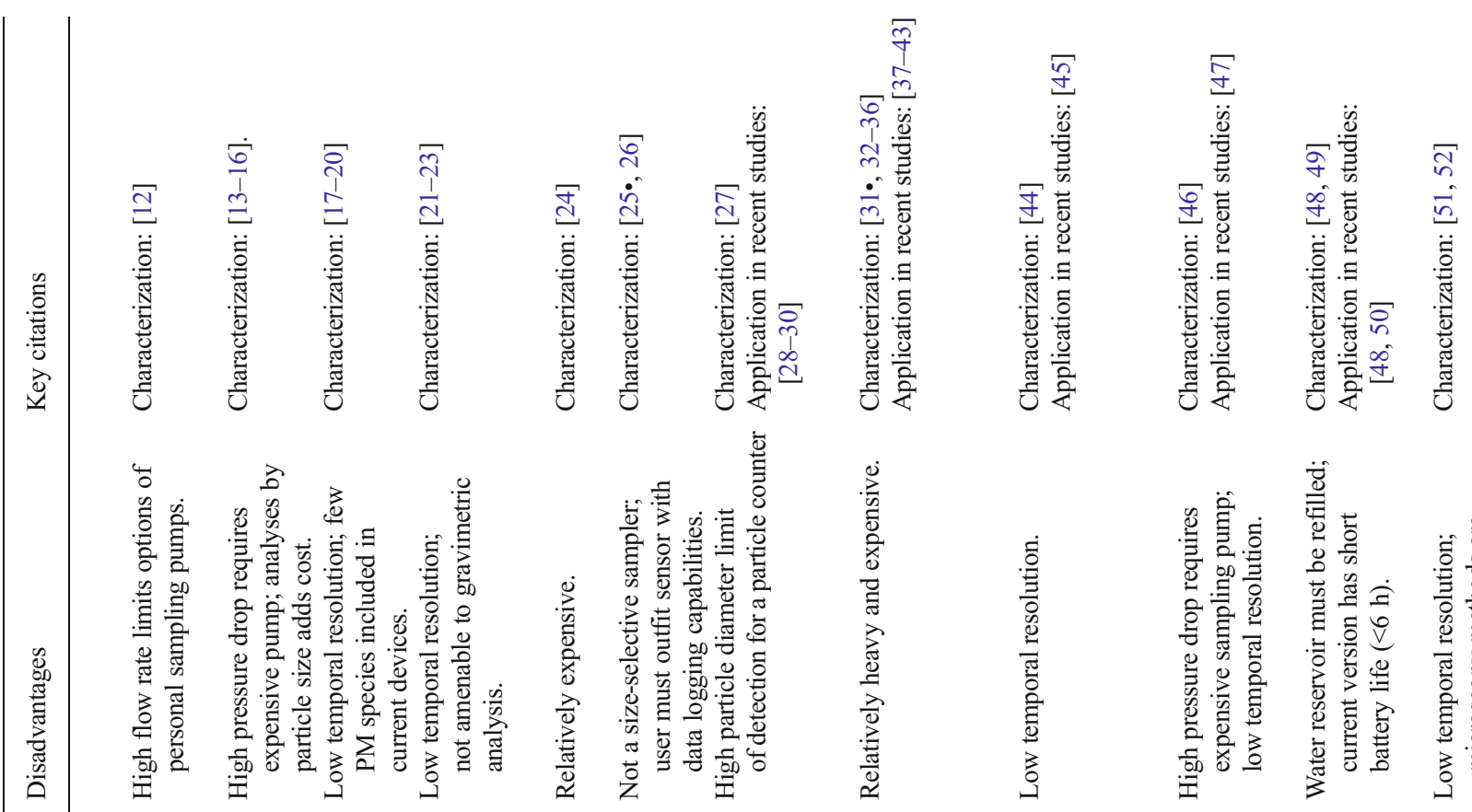

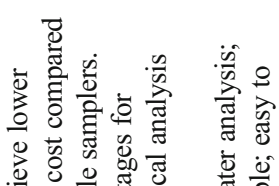

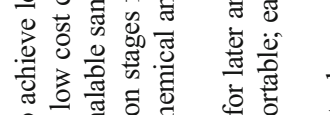

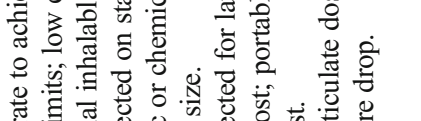

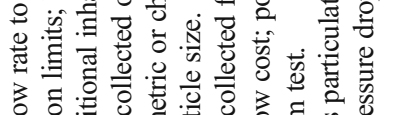

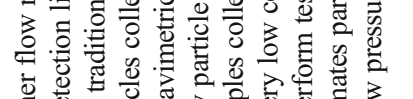

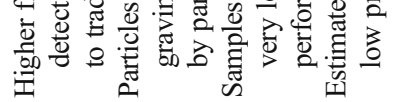

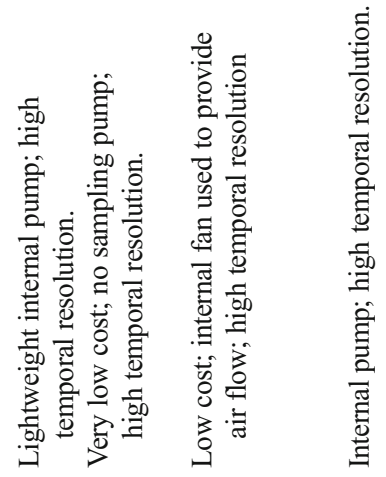

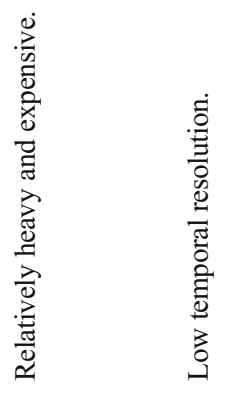

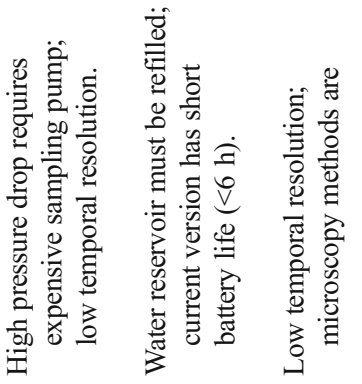

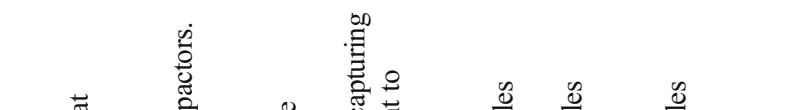

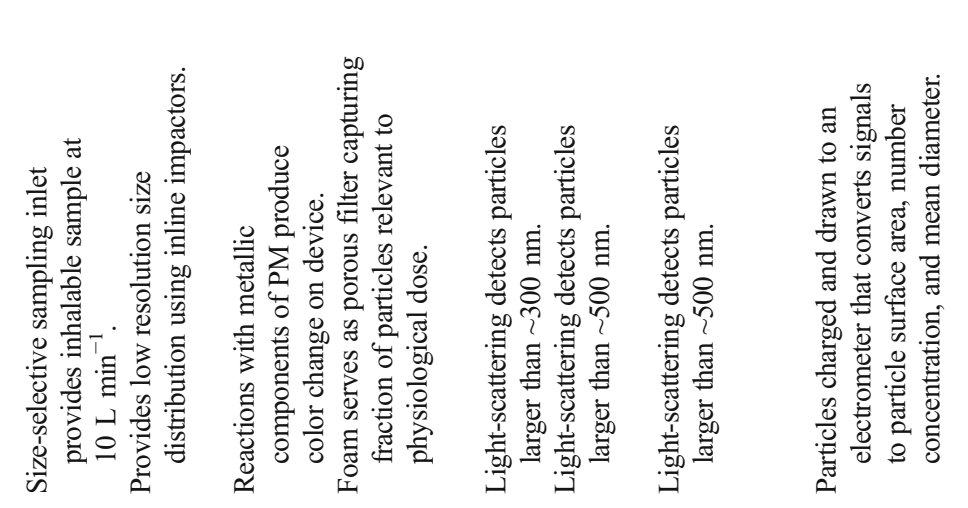

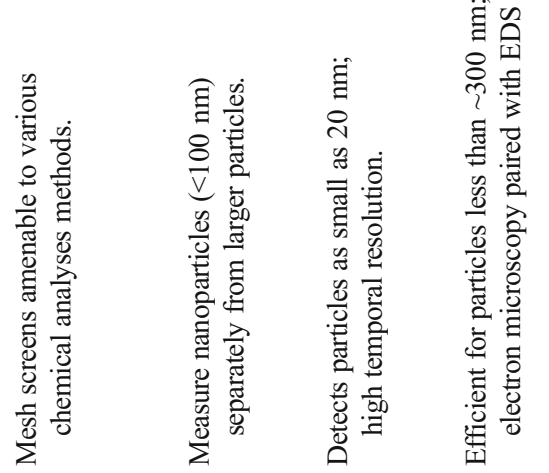

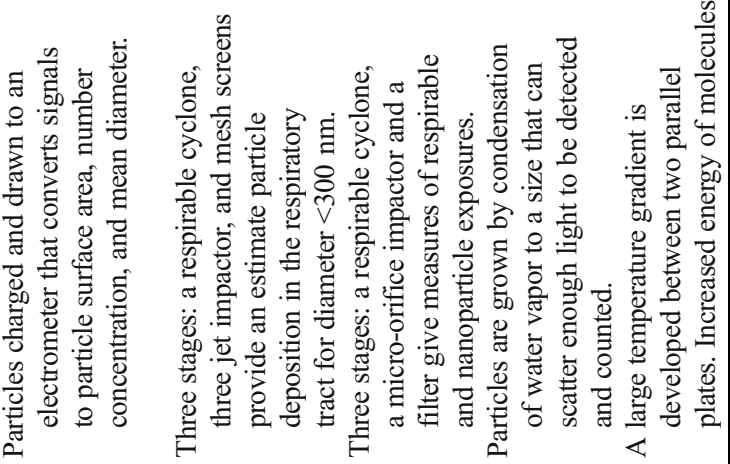

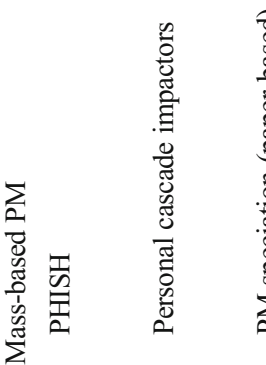

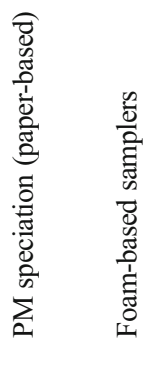

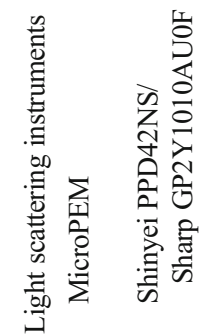

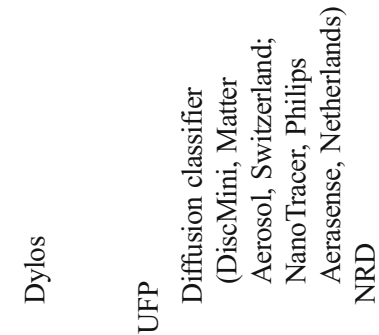<smiles>CC(C)C(C)C</smiles> 
minimize sample losses in existing sampling cassettes. The 37$\mathrm{mm}$ cassette (SKC Inc.) is inexpensive and readily available with preloaded, preweighed filters for easy field use, but does not conform to any of the size selective sampling criteria. The personal high-flow inhalable sampler head (PHISH) adapts a new inlet for the 37-mm cassette to approximate the inhalable criterion when operated at $10 \mathrm{~L} \mathrm{~min}^{-1}$ of flow $[12,69]$. Although the PHISH is not commercially available, it is expected to cost approximately $\$ 10$, a substantial cost savings over the IOM or Button samplers (\$85-250). The increased flow rate of the PHISH compared to the $\operatorname{IOM}\left(2 \mathrm{~L} \mathrm{~min}^{-1}\right)$ or Button sampler $\left(4 \mathrm{~L} \mathrm{~min}^{-1}\right)$ makes this method desirable when sampling durations are short or to achieve method limits of detection for chemical analyses of low concentration species. Another innovation in inhalable sampling is the use of Accu-cap filters (SKC Inc.), which consist of an acid-soluble cellulose acetate capsule attached to filter media (e.g., mixed-cellulose ester, PVC) [70, 71]. The Accu-cap allows quantification of all particles that enter the traditional 37-mm closed-face cassettes, including those caught on the filter and those that would have deposited on the walls of the cassette. Compared to filters alone, significantly more mass has been recovered using the Accu-caps in occupational environments [71].

Personal cascade impactors are also available to obtain the size distribution of a particulate exposure [13, 14]. Cascade impactors consist of sequential impactors in series with decreasing cutoff sizes. Particles above the cutoff size are collected onto impaction substrates, and those particles smaller than the smallest cutoff size are collected onto a filter. The size distribution of the aerosol can then be constructed from analysis of individual substrates. Relatively recent developments in cascade impactors include the use of polyurethane foam as a collection substrate [15] and the development of a microscale impactor using lithography [16].

\section{Direct-Reading Instruments Using Light Scattering}

Light scattering has been used as an indicator of particle concentration for over a century [72]. Photometers are a class of light-scattering device in which an assembly of particles is illuminated within a sensing zone at one time. For particles with a diameter from $\sim 300 \mathrm{~nm}$ to $\sim 10 \mu \mathrm{m}$, the light scattered is proportional to the mass concentration of the aerosol, although the relationship changes with particle type and size distribution [73]. Particles smaller than $300 \mathrm{~nm}$ do not scatter enough light to be detected with a photometer, and particles larger than $10 \mu \mathrm{m}$ are difficult to draw into the sensing zone. Personal, belt-mounted photometers allow rapid (up to $1 \mathrm{~s}$ resolution) measurement of particle mass concentrations, such as the Personal DataRam (pDR-1200 and pDR-1500, \$5500; Thermo Scientific), SidePak (AM510, TSI Inc.), and the microPEM [24]. The pDR-1200 has been evaluated in laboratory tests [74, 75]. Photometers can be operated with a size-selective inlet to obtain 
estimates of particulate matter in various size fractions (e.g., respirable, $\mathrm{PM}_{2.5}$ ). Photometers have been used to assess personal particle exposures in widely varying environments from subway stations [76] to hookah bars [77].

Low-cost sensors $(\sim \$ 15$, Shinyei PPD42NS, and $\sim \$ 12$, Sharp GP2Y1010AU0F) based on photometry have recently become available. The low cost of these sensors is partially enabled because a light-emitting diode is used as the light source. However, these sensors require integration with a data logger or other communication device and an enclosure for environmental use. The Shinyei sensor has been used in a distributed network to measure spatiotemporal variations of $\mathrm{PM}_{2.5}$ in China [25•]. $\mathrm{PM}_{2.5}$ measured with the Shinyei sensor at an EPA monitoring site has been shown to compare favorably to more expensive commercial photometers [26]. Although these sensors have been used as stationary environmental monitors to date, they could be enclosed into a battery-powered unit with data-logging capabilities for personal exposure assessment.

A low-cost, light-scattering device based on particle counting ( $\$ 400, \mathrm{DC} 1700$, Dylos Corp.) has recently been incorporated into environmental studies. In the DC1700, a small box fan pulls particles into a sensing area illuminated by a red laser. The light scattered by an individual particle in the sensing zone is used to place a count into one of two size bins $(>0.5$ or $>2.5 \mu \mathrm{m})$. The output of the Dylos is particle number concentration, which has been shown to scale with particle mass concentration for a given particle type and size distribution [27]. This instrument has been used to measure second hand smoke [28] and as part of an intervention to reduce exposure to second hand smoke [29]. Although rather large, the Dylos has been incorporated into a backpack for personal monitoring [30].

\section{Dose-Based Samplers}

Recently, samplers have been developed to estimate the fraction of particles that deposit in the human respiratory tract using polyurethane foam as a substrate [21, 22]. The foam plugs are small and operate at flow rates amenable to personal sampling. By estimating the deposited fraction, such samplers seek to provide a more physiologically relevant estimate of dose. Foam plugs have a lower pressure drop than traditional filter media, for a given flow rate, that remains constant with loading [21]. As a result, inexpensive pumps may be able to operate foam-based devices without the need for automated flow control that substantially increases the cost of personal sampling pumps. However, this advantage is partially offset by the need for relatively expensive chemical analysis. Foambased samplers are subject to humidity effects resulting in a high gravimetric limit of quantification that makes it impractical for personal sampling over short periods of time $(<24 \mathrm{~h})$ [21]. Instead, researchers have conducted chemical analyses of foam substrates for specific PM components or used them as size-selective inlets to other devices [21, 78-81].

\section{PM Speciation}

There is increasing evidence that some sources of particulate pollution are enriched in metals, polycyclic aromatic hydrocarbons, and other toxic species yielding a mixture that is more detrimental to human health than other sources of pollution. For example, traffic-related air pollution is a particularly toxic component of PM and that it inflicts a major burden on public health [82]. For this reason, personal exposure assessment seeking to evaluate the contribution of specific sources to personal PM exposure have sought more specific metrics than $\mathrm{PM}_{2.5}$ mass, including chemical speciation of tracers compounds that may indicate the influence of specific sources. PM speciation has traditionally involved analyses of samples captured on filter media (e.g., inductively coupled plasma, ICP, followed by optical emission spectrometry, OES, or mass spectrometry, MS). PM speciation is substantially more expensive (often $>\$ 50$ per sample) than gravimetric analysis ( $\sim 15$ per sample), often limiting the number of samples taken in a study. Moreover, method limits of detection often require fairly long sampling durations, which limits measurement time resolution. Advances in microfluidic technology allow for low-cost, rapid detection of some PM species. Paper-based devices have employed colorimetric methods to detect trace species (as low as nanogram masses) in collected air samples and biologic fluids [83]. Paper-based sensors have been developed to measure metals from air samples collected on traditional filtration media [17-19, 84•]. These paper-based devices are very low-cost $(<\$ 1$ to produce, compared to $\sim \$ 100$ for a metal analysis by ICP-MS), can use simple devices like cellular phone cameras as color detectors, and have shown good linearity with traditional methods [83]. Pairing these devices with electrochemical detection can further improve method selectivity and sensitivity [19, 83]. The species available for quantification by this method are still limited, but the "lab on a chip" field is progressing rapidly and may present new opportunities for personal exposure assessment.

Black carbon is produced from the incomplete combustion of fossil fuels. In densely populated areas, the contribution from traffic is often considered more important than from other fossil fuel combustion activities, including industry [85]. In studies collecting PM filter samples, the absorbance of the filter can be measured with a transmissometer to evaluate the mass of black carbon (e.g., SootScan, Magee Scientific, Berkeley, CA, USA). This method can provide estimates of the time weighted average exposure to black carbon [61, $62]$. However, if the goal is to evaluate exposures during commute times specifically, cumulative measures may not be suitable. A personal aethalometer (MicroAeth, AethLabs, San 
Francisco, CA, USA) has gained popularity for measuring black carbon at high temporal resolution (up to 1-s resolution) and for use en epidemiologic studies [57-59].

\section{Beyond PM Mass}

Although it is certain that PM is associated with a variety of adverse health outcomes, it is not known which metric (particle size, morphology, or chemical composition) is most strongly associated with heath deterioration [86-88]. The assessment of personal exposures, which are highly dependent on individual activities, represents an opportunity to evaluate the short-term effects of novel pollution metrics that are not routinely monitored for regulatory purposes. As ambient $\mathrm{PM}_{2.5}$ mass levels improve, especially in many developed regions of the world, other metrics, such as those discussed below, may provide stronger, more precise associations with health outcomes.

\section{Ultrafine Particulates}

Ultrafine particles (UFP, those with diameter less than $\sim 0.1 \mu \mathrm{m}$ ) contribute nearly negligibly to $\mathrm{PM}_{2.5}$ mass, but dominate the particle number concentration (PNC). UFP are known to carry large amounts of adsorbed toxic contaminants such as oxidants, metals, and organic species that may produce oxidative stress in the body [89]. Traditionally, monitoring of UFP has relied on condensation particle counters (CPCs) to measure PNC and handheld units have been used for personal exposure assessment (e.g., P-track, TSI, Inc., Shoreview, MN [90]). However their use in personal monitoring is limited by the cost, size, weight, and maintenance requirements of this instrument.

In the last 5 years, substantial progress has been made to assess personal exposure to ultrafine particles (particles smaller than $100 \mathrm{~nm}$ ). Personal DRIs for ultrafine particles are based on diffusion charging or light scattering after growth by condensation. The DiSCmini (Matter Engineering) is a personal diffusion charging device introduced by Fierz et al. [31•]. In the DiSCmini, a positive corona is used to produce a high concentration of positive ions that attach to the particles entering the inlet. The charged particles then pass through an induction stage (or ion filter), a diffusion stage, and a high efficiency particulate air (HEPA) filter. The diffusion stage and the HEPA filter are each connected to an electrometer, which measures the charge of depositing particles. The smallest particles deposit on the screen in the diffusion stage, whereas larger particles penetrate to the HEPA filter. Particle number concentration, mean diameter, and lung-deposited surface area concentration are estimated using the signals from the electrometers. The DiSCmini compares reasonably well with reference instruments under laboratory $[32,91]$ and field settings [33]. In urban settings, the DiSCmini was used to show that number concentration is generally inversely related to particle size and strongly influenced by microenvironment, number concentrations are highest near roads, and that HEPA filters in cars can substantially reduce exposures [37]. The DiSCmini has also been used to investigate the relationship among particle exposures and cardiovascular health risk during highway maintenance [38] and to investigate the spatial heterogeneity of ultrafine particles [39, 40].

The nanoTracer PNT1000 (Phillips Areasense) is another DRI based on diffusion charging for measuring personal exposure to ultrafine particles. As described by Marra et al. [34], particles entering the nanoTracer are first charged in by diffusion charging and then enter an electrostatic precipitation section. The charge on particles that pass through the precipitator and deposit onto a HEPA filter is measured with an electrometer. The total particle number concentration and mean particle size are derived from the signals of the electrometer with the electrostatic precipitator turned on and off. The nanoTracer has been compared to other instruments in the laboratory $[35,36]$. It has been used to evaluate determinants of ultrafine particle concentrations in homes [92] and to investigate possible associations among ultrafine particle exposures and adverse cardiopulmonary health [41-43].

A personal ultrafine particle monitor (PUFP C100, Enmont LLC) became commercially available in late 2014 as described by Ryan et al. [48]. The PUFP C100 is a CPC that addresses many of the challenges when using CPCs for personal exposure assessment. The $\mathrm{C} 100$ draws aerosol through a tubular saturator with walls wetted with water. The temperature of the saturator is increased with distance causing supersaturation of water vapor at the centerline of the tube and condensation of water vapor onto the surface of the particles larger than a critical diameter $(\sim 20 \mathrm{~nm})$. These particles grow until they are several micrometers in diameter and scatter a sufficient amount of light to be counted in a detector region. This instrument provides total particle number concentration from $\sim 20 \mathrm{~nm}$ to $\sim 2 \mu \mathrm{m}$. However, the CPC must have the water reservoir refilled periodically, which may require assistance from participants for sampling durations over $6 \mathrm{~h}$. Measurements made with prototypes of this instrument have been shown to be highly correlated with those from benchtop, reference CPCs [49]. This instrument and prototypes have been used to investigate the impact of idling of school busses on ultrafine particle exposures $[48,50]$ and to evaluate ultrafine particle exposures among schoolchildren [48].

Other devices have been designed to collect ultrafine particles for subsequent analysis by electron microscopy or bulk chemical methods. Chemical and morphological information from electron microscopy can be used to distinguish certain types of nanoparticles apart from other nanoparticles and larger particles in a collected sample [93], although analysis can be expensive ( $\sim 300$ per sample). Samples collected onto 
filters can be used for this purpose but require a flat featureless background (polycarbonate filters) and correction for less than $100 \%$ collection efficiency [94], which also depends on particle morphology [95]. They also require fairly complicated procedures to eliminate the background filter media for analysis by transmission electron microscopy (TEM), which provides better resolution than scanning electron microscopy (SEM) for particles smaller than $100 \mathrm{~nm}$ [93]. Alternatively, personal thermophoretic samplers to collect breathing zone samples over a fairly long ( $8 \mathrm{~h}$ to $24 \mathrm{~h}$ ) time period directly onto TEM grids $[51,52]$. These grids can then be analyzed by SEM or TEM without further preparation.

Several samplers have been developed to collect ultrafine particles for characterization by bulk chemistry methods. The personal nanoparticle sampler (PENS) uses three stages (a respirable cyclone, a micro-orifice impactor with a $d_{50}=$ $100 \mathrm{~nm}$, and a filter) to enable measurement of respirable and nanoparticle exposures [46]. The impactor provides a sharp cutoff to collect nanoparticles separately from larger particles, although at a rather high pressure drop of $14 \mathrm{kPa}$. Another sampler, the nanoparticle respiratory deposition (NRD) sampler (Zefon Intl) [44], uses a respirable cyclone $\left(d_{50}=4 \mu \mathrm{m}\right)$, a three-jet impactor $\left(d_{50}=300 \mathrm{~nm}\right)$, and finally eight nylon mesh screens to collect particles by diffusion. The collection efficiency of the mesh screens combined with that of the impactor mimics the total deposition of particles smaller than $300 \mathrm{~nm}$ in the human respiratory system. The reliance of particle collection by diffusion enables particle collection at substantially lower pressure drop than the PENS $(3.5 \mathrm{kPa})$, which is important for personal sampling pumps. The filter from the PENS or the mesh screens from the NRD sampler can be analyzed by various chemical methods (e.g., inductively coupled plasma followed by optical emission spectroscopy, ICP-OES). The PENS sampler has been used for sampling of metalworking operations [47], and the NRD sampler for assessing welding fume exposures [45].

\section{Oxidative Capacity}

Although the exact mechanisms by which PM leads to adverse health outcomes are not entirely clear, exposure to PM has been shown to generate reactive oxygen species (ROS) and produce oxidative stress in cells [3, 96-98]. Persistent cellular oxidative stress may lead to cellular damage, cell death, and disease $[3,99]$. Because a wide variety of species can produce these ROS, measuring these components of PM individually is not practical or cost-effective. Instead, chemical assays such as the dithiothreitol assay have been developed to assess the cumulative effect of these components to produce ROS, known as the aerosol oxidative capacity [100-104]. The dithiothreitol assay typically requires relatively large masses of PM (5-40 $\mu$ g per $\mathrm{mL}[101,102])$, necessitating sampling flow rates and durations longer than the typical for personal monitoring. Recent advances in microfluidic technology have reduced the assay volumes such that low PM masses can be evaluated with a paper-based device [63, 64], similarly as described for the detection of metals ("Section 2.4) and electrochemical sensors have been developed that can be used to measure oxidative capacity in airborne PM [105] or from extracted filter samples [106]. Both the electrochemical and paper-based devices have potential uses for personal exposure assessment.

\section{Integration of Exposure Covariates}

Epidemiologic analysis requires the collection of health measures and other important covariates often through questionnaires and exam visits. However, questionnaire data can be unreliable and subject to recall bias, and in most cases, it is unclear when exam visits should be scheduled (immediately after sampling, $8 \mathrm{~h}$ later, $24 \mathrm{~h}$ later). Several new approaches are described here to improve collection of these data.

\section{Microenvironment and Location}

As individuals move through an urban or suburban environment, pollution levels within their breathing zone may change rapidly with location (e.g., major roads versus office space) and time (e.g., rush-hour traffic versus weekend drive). Time activity diaries are often used to account for participant location, but these diaries are time-consuming for participants, and are often incomplete. Alternately, personal exposure assessment using direct-reading sensors can be paired with a global positioning system (GPS) receiver to track participant location [107]. Downloading the time series of participant location into a geographic information system (GIS) with known home, work, and asking participants about other locations visited during their sampling period can provide a more precise estimate of time activity.

\section{Activity Level}

Although personal monitoring is the state-of-the-art method for exposure assessment, an estimate of inhaled dose cannot be made without knowledge of ventilation rate. According to the environmental health paradigm, inhaled dose should be more related to the health outcome than the exposure. Although it is possible to measure ventilation rate directly, such instruments require participants to wear chest straps that are uncomfortable for most. Ventilation rate is related to heart rate [24], and commercially available heart rate monitors may provide an opportunity to improve estimates of participant dose, particularly for activities like riding a bicycle, where both exposure and ventilation rate may be high. 
Sophisticated chest-mounted heart rate monitors (e.g., ActiHeart, CamNtech) provide high quality data and can additionally monitor interbeat interval also providing measurements of heart rate variability, which may be an important health outcome to consider in studies on impacts of PM on cardiovascular health [108]. However, relatively inexpensive heart rate monitors that are wrist mounted may also prove useful to determine inhaled dose.

\section{Health Data}

Several recent studies have deployed home-use spirometers for panel studies of asthma and COPD patients [109-111]. These studies showed that data-logging units prevented transcription errors by participants, improved compliance, and provided data that compared well to clinic spirometers. Ambulatory heart rate monitors have also been used in epidemiologic studies of air pollution, but are bulky and uncomfortable for many participants. Small, wearable sensors are marketed to elite athletes, but have clear usefulness for personal monitoring. Commercial sensors for cardiac rhythm are now available (e.g., ZioPatch, iRhythm Technologies, and other sensors that can monitor blood chemistry are under development [112]). Additionally, sensors to track outcomes among susceptible populations may improve our understanding of how particulate air pollution contributes to disease. For example, units adapted to fit on an inhaler can track usage and the location of use of rescue medication for individuals with asthma or chronic obstructive pulmonary disease (Doser, Meditrack Products; Propeller, Propeller Health).

\section{Outstanding Challenges and Opportunities in Air Pollution Exposure Assessment}

A major limitation of personal exposure assessment is determining whether the participant has worn sampling equipment consistently (participant compliance). If sampling equipment is left in a home unattended, it does no better at reducing exposure misclassification than an area sample. Accelerometers on sampling equipment can be used to determine how long it remained stationary. To characterize the health effects associated with short-term $(<2 \mathrm{~h})$ exposures, it will likely be necessary to have a better awareness of participant compliance. Other methodologies, such as proximity sensors that estimate the distance between the participant and the sampling equipment may be better suited to reach these goals.

We have outlined a framework in Fig. 1 by which sensor data on personal exposures, microenvironmental data, and health data can be collected simultaneously and integrated with a central server to enable high level processing. With rapidly advancing sensor technology, it is crucial that methodology is developed to use the data appropriately. Ramachandran and colleagues [113, 114] showed that 15min average ambient air pollutant concentrations were routinely 3-4 times higher than the 24-h average outdoor values, could vary by as much as an order of magnitude, and that within-day variability was comparable to between-day variability. Variability in personal exposures will likely be even larger than ambient levels because participants are actively involved with PM generating processes (cooking, cleaning, driving etc.). However, this data will also be correlated over time, complicating statistical analyses. DRIs can often provide
Fig. 1 Framework for personal exposure assessment and usage of highly resolved temporal data

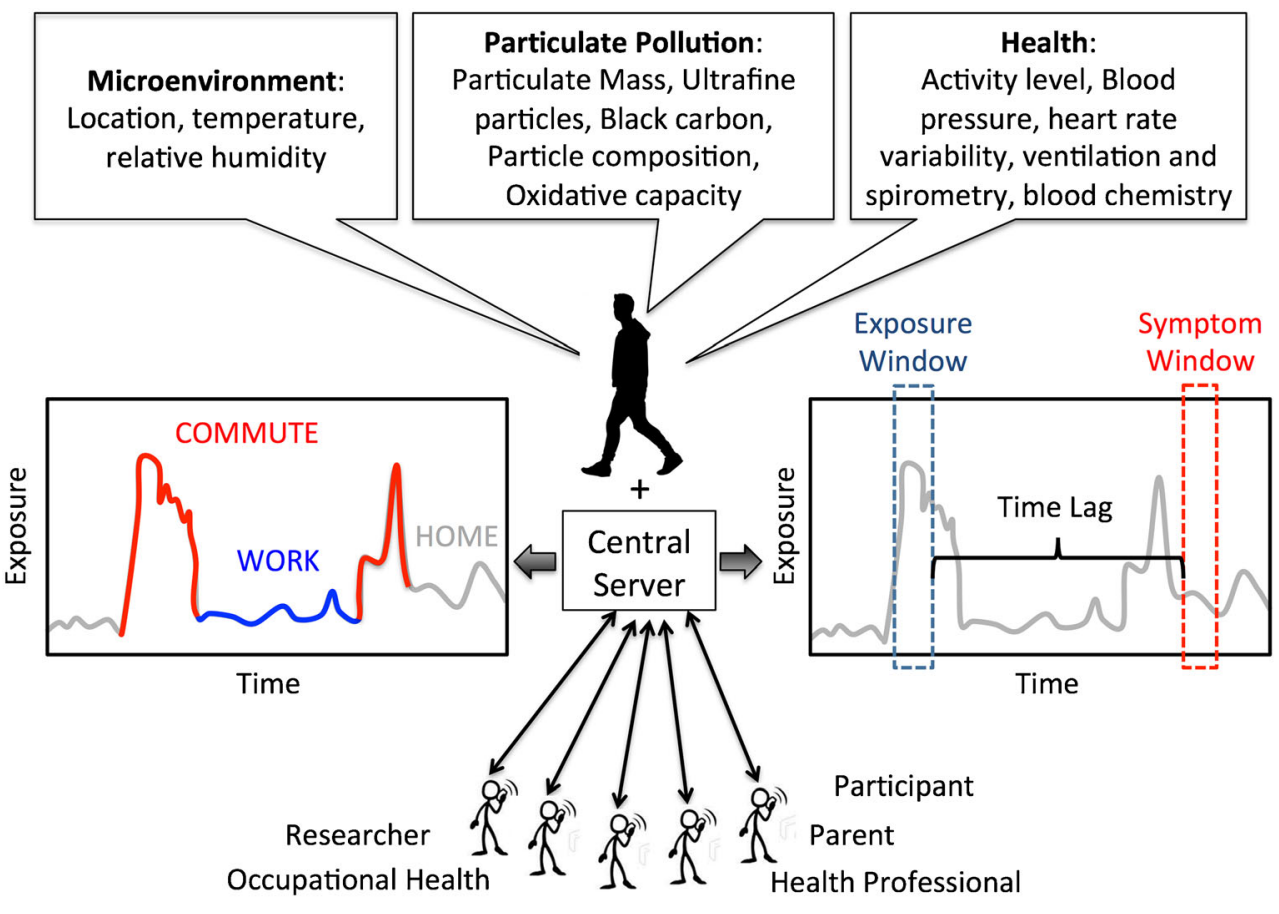


high temporal resolution data, but most studies have not been utilizing this kind of data, and are instead simply averaging over longer time frames based on some classification (hourly, by microenvironment, etc.). However, these data have potential to help elucidate the appropriate time frame from exposure to health outcome. In the lower right panel of Fig. 1, we illustrate how floating exposure and health outcome windows can be modeled to define the most relevant lag times for health effects. Wellenius et al. [6] found that ischemic stroke risk was most strongly associated with markers of traffic-related pollution (hourly $\mathrm{PM}_{2.5}$ mass, black carbon, nitrogen dioxide concentrations) with the highest odds ratios occurring 12-14 h before stroke onset, suggesting that short-term exposures may increase risk. Significant associations were not observed for sulfate, ozone, or carbon monoxide. Additionally, Delfino et al. [110] found stronger associations between FEV1 and $\mathrm{PM}_{2.5}$ mass when 1 and 8-h maximum values were used, compared to 24-h averages among asthmatic children. Developing data handling and statistical methodology will be crucial to use this high resolution data appropriately while properly accounting for measurement error, correlation, and confounding $[115,116]$.

The combination of location and exposure data allows researchers to apportion exposures to the various microenvironments in which people spend time and may help identify sources most strongly associated with health (Fig. 1, lower left panel). For example, when a person is at home, the PM from vacuuming or cooking may not be associated with health outcomes to the same extent as traffic-related particulate air pollution that is enriched in black carbon, metals, and polycyclic aromatic hydrocarbons when a person is in transit [82]. Such results may have important policy implications. The persistent observation of health effects at PM concentrations below regulatory standards suggests that there may not be a threshold level for which the effects of PM on health are not observed [117]. The lack of a threshold complicates policy decisions because reductions in PM mass concentrations will ultimately be limited by background concentrations from natural sources. Currently, regulations are based on central monitoring of mass concentration. Mass-only measurements are inherently difficult to use to identify the most toxic particles from the highly variable mixture encountered in daily life. Epidemiologic studies that employ personal exposure assessment may provide needed information on the associations of specific components of PM and health. Such monitoring, including both novel metrics of air pollution and acute health information, could provide a basis for evaluating variable toxicity of different sources of PM or components of PM. This information may allow individuals, particularly those most susceptible to the adverse effects of air pollution, to make choices to reduce their exposures to the most toxic components of PM. Ultimately, the information may contribute to new regulations or guidance honed to those specific sources of PM or components of PM (e.g., chemical composition, size, shape) most strongly associated with adverse health.

Other challenges in monitoring airborne particle exposures in different microenvironments remain. For example, due to differences in sampling approaches for PM in occupational and ambient environments (e.g., respirable mass for occupational exposure assessment vs. $\mathrm{PM}_{2.5}$ mass for ambient exposure assessment) and differing mandates from distinct funding agencies (EPA and NIEHS vs. NIOSH), few studies have considered exposure assessments in both ambient and occupational environments. This distinction leaves researchers unable to consider a holistic view of PM exposure for individuals. Other challenges include agreement from participants' employers to allow monitoring equipment in the workplace. However, low-cost and lightweight monitoring instruments can improve the feasibility of studies to cross these domains.

Finally, we wish to identify a few opportunities for integration of new sensor technology for exposure and health data between researchers, participants, and other stakeholders (Fig. 1, lower center panel). High temporal resolution data could be wirelessly transmitted to participant computers or cell phones, allowing them on-demand information of their exposures and enabling them to view how personal activities influence their personal exposures. In occupational environments, such sensors could trigger alarms for health and safety professionals to let them know when exposure thresholds are exceeded. Health and exposure data could be sent to parents of susceptible children or to health professionals of susceptible populations of children and adults (e.g., asthmatics, those with cardiovascular disease) to allow immediate intervention when needed to minimize or prevent exacerbation of disease.

\section{Conclusions}

Personal monitoring for particulate air pollution was pioneered in the 1960s, but significant advances in pump, sensor, and battery technology have improved the reliability of these sampling methods and improved feasibility for largescale personal exposure assessment. This review has outlined personal exposure assessment approaches focusing on novel sensors developed over the last 5 years. Although sizeselective sampling remains the most common method for measuring personal exposures to particulates, novel sensors that go beyond measuring PM mass provide alternate strategies for exposure assessment and may yield stronger, more precise associations with adverse health outcomes accounting for the variability introduced by the toxicity of sources. For example, particle number concentration is dominated by the smallest particles $(<200 \mathrm{~nm})$, those which contribute nearly negligibly to particle mass concentration. Until recently, particle number concentration was difficult to measure without the aid of heavy and expensive equipment, but personal 
monitors employing at least five measurement methods have been developed over the last 5-10 years. By pairing traditional or novel exposure measures with measures of health, activity, and important microenvironmental factors, we anticipate that information bias can be reduced compared to questionnairebased approaches and central monitoring. More importantly, a holistic view of the influence of particulate air pollution on health may emerge.

\section{Compliance with Ethics Guidelines}

Conflict of Interest Kirsten A. Koehler declares that she has no conflict of interest. Thomas Peters has a patent US20130220034 A1 with royalties paid to the University of Iowa.

Human and Animal Rights and Informed Consent This article does not contain any studies with human or animal subjects performed by any of the authors.

\section{References}

Papers of particular interest, published recently, have been highlighted as:

- Of importance

1. Lim SS, Vos T, Flaxman AD, Danaei G, Shibuya K, Adair-Rohani $\mathrm{H}$, et al. A comparative risk assessment of burden of disease and injury attributable to 67 risk factors and risk factor clusters in 21 regions, 1990-2010: a systematic analysis for the global burden of disease study 2010. Lancet. 2012;380(9859):2224-60.

2. Brook RD. Cardiovascular effects of air pollution. Clin Sci. 2008;115(5-6):175-87. doi:10.1042/Cs20070444.

3. Brook RD, Rajagopalan S, Pope CA, Brook JR, Bhatnagar A, Diez-Roux AV, et al. Particulate matter air pollution and cardiovascular disease an update to the scientific statement from the American Heart Association. Circulation. 2010;121(21):233178. doi:10.1161/Cir.0b013e3181dbece1.

4. Dominici F, Peng RD, Bell ML, Pham L, McDermott A, Zeger $\mathrm{SL}$, et al. Fine particulate air pollution and hospital admission for cardiovascular and respiratory diseases. Jama-J Am Med Assoc. 2006;295(10):1127-34. doi:10.1001/Jama.295.10.1127.

5. Krall JR, Anderson GB, Dominici F, Bell ML, Peng RD. Shortterm exposure to particulate matter constituents and mortality in a national study of US urban communities. Environ Health Perspect. 2013;121(10):1148-53. doi:10.1289/Ehp.1206185.

6. Wellenius GA, Burger MR, Coull BA, Schwartz J, Suh HH, Koutrakis $\mathrm{P}$, et al. Ambient air pollution and the risk of acute ischemic stroke. Arch Intern Med. 2012;172(3):229-34.

7. Rice MB, Ljungman PL, Wilker EH, Gold DR, Schwartz JD, Koutrakis P, et al. Short-term exposure to air pollution and lung function in the Framingham Heart Study. Am J Resp Crit Care. 2013;188(11):1351-7. doi:10.1164/Rccm.201308-1414oc.

8. Johannesson S, Rappaport SM, Sallsten G. Variability of environmental exposure to fine particles, black smoke, and trace elements among a Swedish population. J Expo Sci Env Epid. 2011;21(5): 506-14.
9. Bureau oLS. Summary table B. Employment, hours, and earnings of employees on nonfarm payrolls, seasonally adjusted. 2012. $\mathrm{ftp} / / / \mathrm{ftp}$. bls.gov/pub/suppl/empsit.cessum.txt. Accessed 3/8/2012.

10. Sherwood R, Greenhalgh D. A personal air sampler. Ann Occup Hyg. 1960;2(2):127-32.

11. Vincent JH. Occupational and environmental aerosol exposure assessment: a scientific journey from the past, through the present and into the future. J Environ Monitor. 2012;14(2):340-7. doi:10. 1039/C1em10586h.

12. Koehler KA, Anthony TR, Van Dyke M, Volckens J. Solid versus liquid particle sampling efficiency of three personal aerosol samplers when facing the wind. Ann Occup Hyg. 2012;56(2):194206. doi:10.1093/annhyg/mer077.

13. Misra C, Singh M, Shen S, Sioutas C, Hall PM. Development and evaluation of a personal cascade impactor sampler (PCIS). J Aerosol Sci. 2002;33(7):1027-47.

14. Rubow KL, Marple VA, Olin J, McCawley MA. A personal cascade impactor: design, evaluation, and calibration. Am Ind Hyg Assoc J. 1987;48:532-8.

15. Demokritou P, Lee SJ, Ferguson ST, Koutrakis P. A compact multistage (cascade) impactor for the characterization of atmospheric aerosols. J Aerosol Sci. 2004;35(3):281-99.

16. Kang JS, Lee KS, Lee KH, Sung HJ, Kim SS. Characterization of a microscale cascade impactor. Aerosol Sci Technol. 2012;46(9): 966-72.

17. Cate D, Volckens J, Henry C. Personal exposure assessment to particulate metals using a paper-based analytical device. Proc Spie. 2013;8615. doi: 10.1117/12.2005656.

18. Cate DM, Nanthasurasak P, Riwkulkajorn P, L'Orange C, Henry CS, Volckens J. Rapid detection of transition metals in welding fumes using paper-based analytical devices. Ann Occup Hyg. 2014;58(4):413-23. doi:10.1093/Annhyg/Met078.

19. Rattanarat P, Dungchai W, Cate D, Volckens J, Chailapakul O, Henry CS. Multilayer paper-based device for colorimetric and electrochemical quantification of metals. Anal Chem. 2014;86(7):3555-62. doi:10.1021/Ac5000224.

20. Rattanarat P, Dungchai W, Cate DM, Siangproh W, Volckens J, Chailapakul O, et al. A microfluidic paper-based analytical device for rapid quantification of particulate chromium. Anal Chim Acta. 2013;800:50-5. doi:10.1016/J.Aca.2013.09.008.

21. Koehler KA, Clark P, Volckens J. Development of a sampler for total aerosol deposition in the human respiratory tract. Ann Occup Hyg. 2009;53(7):731-8. doi:10.1093/Annhyg/Mep053.

22. Kuo YM, Huang SH, Shih TS, Chen CC, Weng YM, Lin WY. Development of a size-selective inlet-simulating ICRP lung deposition fraction. Aerosol Sci Technol. 2005;39(5):437-43.

23. Vincent JH, Aitken RJ, Mark D. Porous plastic foam filtration media - penetration characteristics and applications in particle size-selective sampling. J Aerosol Sci. 1993;24(7):929-44.

24. Rodes C, Chillrud S, Haskell W, Intille S, Albinali F, Rosenberger M. Predicting adult pulmonary ventilation volume and wearing compliance by on-board accelerometry during personal level exposure assessments. Atmos Environ. 2012;57:126-37.

25. Gao M, Cao J, Seto E. A distributed network of low-cost continuous reading sensors to measure spatiotemporal variations of PM2.5 in Xi'an, China. Environ Pollut. 2015;199:56-65. This study shows how low cost sensors can be applied for ambient monitoring of PM. Such sensors are likely also useful for personal monitoring.

26. Holstius D, Pillarisetti A, Smith K, Seto E. Field calibrations of a low-cost aerosol sensor at a regulatory monitoring site in California. Atmos Meas Tech. 2014;7(4):1121-31.

27. Northcross AL, Edwards RJ, Johnson MA, Wang Z-M, Zhu K, Allen T, et al. A low-cost particle counter as a realtime fineparticle mass monitor. Environ Sci: Proc Impacts. 2013;15(2): 433-9. 
28. Semple S, Ibrahim AE, Apsley A, Steiner M, Turner S. Using a new, low-cost air quality sensor to quantify second-hand smoke (SHS) levels in homes. Tobacco control. 2013:tobaccocontrol2013-051188.

29. Klepeis NE, Hughes SC, Edwards RD, Allen T, Johnson M, Chowdhury Z, et al. Promoting smoke-free homes: a novel behavioral intervention using real-time audio-visual feedback on airborne particle levels. PLoS One. 2013;8(8), e73251.

30. Steinle S, Reis S, Sabel CE, Semple S, Twigg MM, Braban CF, et al. Personal exposure monitoring of PM2.5 in indoor and outdoor microenvironments. Sci Total Environ. 2015;508:383-94.

31. Fierz M, Houle C, Steigmeier P, Burtscher H. Design, calibration, and field performance of a miniature diffusion size classifier. Aerosol Sci Technol. 2011;45(1):1-10. This study describes the development of a sampler to estimate ultrafine particle concentrations in a wearable sensor.

32. Mills JB, Park JH, Peters TM. Comparison of the DiSCmini aerosol monitor to a handheld condensation particle counter and a scanning mobility particle sizer for submicrometer sodium chloride and metal aerosols. J Occup Environ Hyg. 2013;10(5):250-8.

33. Meier R, Clark K, Riediker M. Comparative testing of a miniature diffusion size classifier to assess airborne ultrafine particles under field conditions. Aerosol Sci Technol. 2013;47(1):22-8.

34. Marra J, Voetz M, Kiesling H-J. Monitor for detecting and assessing exposure to airborne nanoparticles. J Nanoparticle Res. 2010;12(1):21-37.

35. Asbach C, Kaminski H, Von Barany D, Kuhlbusch TAJ, Monz C, Dziurowitz N, et al. Comparability of portable nanoparticle exposure monitors $\Downarrow$. Ann Occup Hyg. 2012;56(5):606-21.

36. Bekö G, Kjeldsen BU, Olsen Y, Schipperijn J, Wierzbicka A, Karottki DG, et al. Contribution of various microenvironments to the daily personal exposure to ultrafine particles: personal monitoring coupled with GPS tracking. Atmos Environ. 2015;110: 122-9.

37. Spinazzè A, Cattaneo A, Scocca DR, Bonzini M, Cavallo DM. Multi-metric measurement of personal exposure to ultrafine particles in selected urban microenvironments. Atmos Environ. 2015;110:8-17.

38. Meier R, Cascio WE, Ghio AJ, Wild P, Danuser B, Riediker M. Associations of short-term particle and noise exposures with markers of cardiovascular and respiratory health among highway maintenance workers. Environ Health Perspect. 2014;122(7):726.

39. Meier R, Eeftens M, Aguilera I, Phuleria HC, Ineichen A, Davey $\mathrm{M}$, et al. Ambient ultrafine particle levels at residential and reference sites in urban and rural Switzerland. Environ Sci Technol. 2015;49(5):2709-15.

40. Ruths M, von Bismarck-Osten C, Weber S. Measuring and modelling the local-scale spatio-temporal variation of urban particle number size distributions and black carbon. Atmos Environ. 2014;96:37-49.

41. Olsen Y, Karottki DG, Jensen DM, Bekö G, Kjeldsen BU, Clausen $\mathrm{G}$, et al. Vascular and lung function related to ultrafine and fine particles exposure assessed by personal and indoor monitoring: a cross-sectional study. Environ Heal. 2014;13(1):112.

42. Karottki DG, Beko G, Clausen G, Madsen AM, Andersen ZJ, Massling A, et al. Cardiovascular and lung function in relation to outdoor and indoor exposure to fine and ultrafine particulate matter in middle-aged subjects. Environ Int. 2014;73:372-81. doi: 10.1016/j.envint.2014.08.019.

43. Karottki DG, Spilak M, Frederiksen M, Jovanovic Andersen Z, Madsen AM, Ketzel M, et al. Indoor and outdoor exposure to ultrafine, fine and microbiologically derived particulate matter related to cardiovascular and respiratory effects in a panel of elderly urban citizens. Int J Environ Res Public Health. 2015;12(2):166786.
44. Cena LG, Anthony TR, Peters TM. A personal nanoparticle respiratory deposition (NRD) sampler. Environ Sci Technol. 2011;45(15):6483-90. doi:10.1021/es201379a.

45. Cena L, Keane M, Chisholm W, Stone S, Harper M, Chen B. A novel method for assessing respiratory deposition of welding fume nanoparticles. J Occup Environ Hyg. 2014;11(12):771-80.

46. Tsai CJ, Liu CN, Hung SM, Chen SC, Uang SN, Cheng Y et al. A Novel Active Personal Nanoparticle Sampler (PENS) for the Exposure Assessment of Nanoparticles in Workplaces. 2012.

47. Young L-H, Lin Y-H, Lin T-H, Tsai P-J, Wang Y-F, Hung S-M, et al. Field application of a newly developed personal nanoparticle sampler to selected metalworking operations. Aerosol Air Qual Res. 2013;13(3):849-61.

48. Ryan PH, Son SY, Wolfe C, Lockey J, Brokamp C, LeMasters G. A field application of a personal sensor for ultrafine particle exposure in children. Sci Total Environ. 2015;508:366-73.

49. He X, Son S-Y, James K, Yermakov M, Reponen T, McKay RT, et al. Analytical performance issues: exploring a novel ultrafine particle counter for utilization in respiratory protection studies. $\mathbf{J}$ Occup Environ Hyg. 2013;10(4):D52-4.

50. Ryan PH, Reponen T, Simmons M, Yermakov M, Sharkey K, Garland-Porter D, et al. The impact of an anti-idling campaign on outdoor air quality at four urban schools. Environ Sci: Proc Impacts. 2013;15(11):2030-7.

51. Thayer D, Koehler K, Marchese A, Volckens J. A personal, thermophoretic sampler for airborne nanoparticles. Aerosol Sci Technol. 2011;45(6):744-50.

52. Azong-Wara N, Asbach C, Stahlmecke B, Fissan H, Kaminski H, Plitzko S, et al. Design and experimental evaluation of a new nanoparticle thermophoretic personal sampler. J Nanoparticle Res. 2013;15(4):1-12.

53. Cheng YH, Lin MH. Real-time performance of the microAeth (R) AE51 and the effects of aerosol loading on its measurement results at a traffic site. Aerosol Air Qual Res. 2013;13(6):1853-63. doi: 10.4209/Aaqr.2012.12.0371.

54. Cai J, Yan BZ, Ross J, Zhang DN, Kinney PL, Perzanowski MS, et al. Validation of MicroAeth (R) as a black carbon monitor for fixed-site measurement and optimization for personal exposure characterization. Aerosol Air Qual Res. 2014;14(1):1-9. doi:10. 4209/Aaqr.2013.03.0088.

55. Delgado-Saborit JM. Use of real-time sensors to characterise human exposures to combustion related pollutants. J Environ Monitor. 2012;14(7):1824-37. doi:10.1039/C2em10996d.

56. Nieuwenhuijsen MJ, Donaire-Gonzalez D, Rivas I, de Castro M, Cirach M, Hoek G, et al. Variability in and agreement between modeled and personal continuously measured black carbon levels using novel smartphone and sensor technologies. Environ Sci Technol. 2015;49(5):2977-82. doi:10.1021/es505362x.

57. Dons E, Panis LI, Van Poppel M, Theunis J, Wets G. Personal exposure to black carbon in transport microenvironments. Atmos Environ. 2012;55:392-8. doi:10.1016/J.Atmosenv.2012.03.020.

58. Klompniaker JO, Montagne DR, Meliefste K, Hoek G, Brunekreef B. Spatial variation of ultrafine particles and black carbon in two cities: results from a short-term measurement campaign. Sci Total Environ. 2015;508:266-75. doi:10.1016/j. scitotenv.2014.11.088.

59. Louwies T, Nawrot T, Cox B, Dons E, Penders J, Provost E, et al. Blood pressure changes in association with black carbon exposure in a panel of healthy adults are independent of retinal microcirculation. Environ Int. 2015;75:81-6. doi:10.1016/j.envint.2014.11. 006.

60. Hinds WC. Aerosol technology: properties, behavior, and measurement of airborne particles. 2nd ed. New York: Wiley; 1999.

61. Schembari A, Triguero-Mas M, de Nazelle A, Dadvand P, Vrijheid $\mathrm{M}$, Cirach $\mathrm{M}$, et al. Personal, indoor and outdoor air pollution 
levels among pregnant women. Atmos Environ. 2013;64:287-95. doi:10.1016/J.Atmosenv.2012.09.053.

62. Huang W, Baumgartner J, Zhang YX, Wang YQ, Schauer JJ. Source apportionment of air pollution exposures of rural Chinese women cooking with biomass fuels. Atmos Environ. 2015;104: 79-87. doi:10.1016/J.Atmosenv.2014.12.066.

63. Dungchai W, Sameenoi Y, Chailapakul O, Volckens J, Henry CS. Determination of aerosol oxidative activity using silver nanoparticle aggregation on paper-based analytical devices. Analyst. 2013;138(22):6766-73. doi:10.1039/C3an01235b.

64. Sameenoi Y, Panymeesamer P, Supalakorn N, Koehler K, Chailapakul O, Henry CS, et al. Microfluidic paper-based analytical device for aerosol oxidative activity. Environ Sci Technol. 2013;47(2):932-40. doi:10.1021/Es304662w.

65. Ozkaynak H, Xue J, Spengler J, Wallace L, Pellizzari E, Jenkins P. Personal exposure to airborne particles and metals: results from the particle team study in riverside, California. J Expo Anal Environ Epidemiol. 1995;6(1):57-78.

66. Van Ryswyk K, Wheeler AJ, Wallace L, Kearney J, You H, Kulka $\mathrm{R}$, et al. Impact of microenvironments and personal activities on personal PM2.5 exposures among asthmatic children. J Expo Sci Environ Epidemiol. 2014;24(3):260-8.

67. Vincent J. Aerosol sampling. Chapter 11: particle size-selective criteria for fine aerosol fractions. Chichester: Wiley; 2007.

68. ACGIH. Threshold limit values and biological exposure indices. Cincinnati: American Conference of Governmental Industrial Hygienists; 2015.

69. Anthony TR, Landazuri AC, Van Dyke M, Volckens J. Design and computational fluid dynamics investigation of a personal, high flow inhalable sampler. Ann Occup Hyg. 2010;54(4):427-42. doi:10.1093/Annhyg/Meq029.

70. Harper M, Ashley K. Acid-soluble internal capsules for closedface cassette elemental sampling and analysis of workplace Air. J Occup Environ Hyg. 2013;10(6):297-306. doi:10.1080/ 15459624.2013.777310.

71. Lee EG, Chisholm WP, Burns DA, Nelson JH, Kashon ML, Harper M. Comparison of lead and Tin concentrations in air at a solder manufacturer from the closed-face $37-\mathrm{mm}$ cassette with and without a custom cellulose-acetate cassette insert. J Occup Environ Hyg. 2014;11(12):819-25. doi:10.1080/15459624.2014. 925116.

72. Lilienfeld P. Aerosol Photometry: A Brief History. In: Sem GJ, editor. History \& Reviews of Aerosol Science. American Association for Aerosol Research; 2005. p. 113.

73. Thomas A, Gebhart J. Correlations between gravimetry and light scattering photometry for atmospheric aerosols. Atmos Environ. 1994;28(5):935-8.

74. Benton-Vitz K, Volckens J. Evaluation of the pDR-1200 real-time aerosol monitor. J Occup Environ Hyg. 2008;5(6):353-9. doi:10. 1080/15459620802009919.

75. Chakrabarti B, Fine PM, Delfino R, Sioutas C. Performance evaluation of the active-flow personal DataRAM PM2.5 mass monitor (Thermo Anderson pDR-1200) designed for continuous personal exposure measurements. Atmos Environ. 2004;38(20):3329-40. doi:10.1016/j.atmosenv.2004.03.007.

76. Vilcassim MR, Thurston GD, Peltier RE, Gordon T. Black carbon and particulate matter (PM2.5) concentrations in New York City's subway stations. Environ Sci Technol. 2014;48(24):14738-45.

77. Zhou S, Weitzman M, Vilcassim R, Wilson J, Legrand N, Saunders E et al. Air quality in New York City hookah bars. Tobacco control. 2014:tobaccocontrol-2014-051763.

78. Koehler KA, Volckens J. Development of a sampler to estimate regional deposition of aerosol in the human respiratory tract. Ann Occup Hyg. 2013;57(9):1138-47. doi:10.1093/annhyg/met041.

79. Dillner AM, Shafer MM, Schauer JJ. A novel method using polyurethane foam (PUF) substrates to determine trace element concentrations in size-segregated atmospheric particulate matter on short time scales. Aerosol Sci Technol. 2007;41(1):75-85.

80. Sun QY, Alexandrova OA, Herckes P, Allen JO. Quantitative extraction of organic tracer compounds from ambient particulate matter collected on polymer substrates. Talanta. 2009;78(3): 1115-21. doi:10.1016/J.Talanta.2009.01.039.

81. Upadhyay N, Majestic BJ, Prapaipong P, Herckes P. Evaluation of polyurethane foam, polypropylene, quartz fiber, and cellulose substrates for multi-element analysis of atmospheric particulate matter by ICP-MS. Anal Bioanal Chem. 2009;394(1):255-66. doi:10. 1007/S00216-009-2671-6.

82. HEI. Traffic-related air pollution: a critical review of the literature on emissions, exposure, and health effects. Boston: HEI Panel on the Health Effects of Traffic-Related Air Pollution; 2010.

83. Cate DM, Adkins JA, Mettakoonpitak J, Henry CS. Recent developments in paper-based microfluidic devices. Anal Chem. 2015;87(1):19-41. doi:10.1021/Ac503968p.

84. Mentele MM, Cunningham J, Koehler K, Volckens J, Henry CS. Microfluidic paper-based analytical device for particulate metals. Anal Chem. 2012;84(10):4474-80. doi:10.1021/Ac300309c. This study presents a methodology for low-cost speciation of constituents likely to be important in determining particle toxicity.

85. Liu W, Wang YH, Russell A, Edgerton ES. Atmospheric aerosol over two urban-rural pairs in the southeastern united states: chemical composition and possible sources. Atmos Environ. 2005;39(25):4453-70. doi:10.1016/J.Atmosenv.2005.03.048.

86. Buonanno G, Stabile L, Morawska L, Russi A. Children exposure assessment to ultrafine particles and black carbon: the role of transport and cooking activities. Atmos Environ. 2013;79:53-8. doi:10.1016/J.Atmosenv.2013.06.041.

87. Strak M, Janssen NAH, Godri KJ, Gosens I, Mudway IS, Cassee FR, et al. Respiratory health effects of airborne particulate matter: the role of particle size, composition, and oxidative potential - the RAPTES project. Environ Health Perspect. 2012;120(8):1183-9. doi:10.1289/Ehp.1104389.

88. Strak M, Hoek G, Godri KJ, Gosens I, Mudway IS, van Oerle R et al. Composition of PM Affects Acute Vascular Inflammatory and Coagulative Markers - The RAPTES Project. Plos One. 2013. 8(3). doi: 10.1371/journal.pone.0058944.

89. Oberdorster G. Pulmonary effects of inhaled ultrafine particles. Int Arch Occ Env Hea. 2001;74(1):1-8.

90. Wallace L, Ott W. Personal exposure to ultrafine particles. J Expo Sci Env Epid. 2011;21(1):20-30. doi:10.1038/Jes.2009.59.

91. Bau S, Zimmermann B, Payet R, Witschger O. A laboratory study of the performance of the handheld diffusion size classifier (DiSCmini) for various aerosols in the $15-400 \mathrm{~nm}$ range. Environ Sci: Proc Impacts. 2015.

92. Bekö G, Weschler CJ, Wierzbicka A, Karottki DG, Toftum J, Loft $\mathrm{S}$, et al. Ultrafine particles: exposure and source apportionment in 56 Danish homes. Environ Sci Technol. 2013;47(18):10240-8.

93. Peters TM, Elzey S, Johnson R, Park H, Grassian VH, Maher T, et al. Airborne monitoring to distinguish engineered nanomaterials from incidental particles for environmental health and safety. J Occup Environ Hyg. 2009;6(2):73-81.

94. Cyrs W, Boysen D, Casuccio G, Lersch T, Peters T. Nanoparticle collection efficiency of capillary pore membrane filters. J Aerosol Sci. 2010;41(7):655-64.

95. Chen S-C, Wang J, Fissan H, Pui DY. Exposure assessment of nanosized engineered agglomerates and aggregates using Nuclepore filter. J Nanoparticle Res. 2013;15(10):1-15.

96. Sioutas C, Delfino RJ, Singh M. Exposure assessment for atmospheric ultrafine particles (UFPs) and implications in epidemiologic research. Environ Health Perspect. 2005;113(8):947-55. doi: 10.1289/Ehp.7939. 
97. Squadrito GL, Cueto R, Dellinger B, Pryor WA. Quinoid redox cycling as a mechanism for sustained free radical generation by inhaled airborne particulate matter. Free Radic Bio Med. 2001;31(9):1132-8. doi:10.1016/S0891-5849(01)00703-1.

98. Schafer FQ, Buettner GR. Redox environment of the cell as viewed through the redox state of the glutathione disulfide/ glutathione couple. Free Radic Bio Med. 2001;30(11):1191-212. doi:10.1016/S0891-5849(01)00480-4.

99. Li N, Kim S, Wang M, Froines J, Sioutas C, Nel A. Use of a stratified oxidative stress model to study the biological effects of ambient concentrated and diesel exhaust particulate matter. Inhal Toxicol. 2002;14(5):459-86.

100. Rappaport SM, Goldberg M, Susi P, Herrick RF. Excessive exposure to silica in the US construction industry. Ann Occup Hyg. 2003;47(2):111-22. doi:10.1093/Annhyg/Meg025.

101. De Vizcaya-Ruiz A, Gutierrez-Castillo ME, Uribe-Ramirez M, Cebrian ME, Mugica-Alvarez V, Sepulveda J, et al. Characterization and in vitro biological effects of concentrated particulate matter from Mexico City. Atmos Environ. 2006;40: S583-92. doi:10.1016/J.Atmosenv.2005.12.073.

102. Cho AK, Sioutas C, Miguel AH, Kumagai Y, Schmitz DA, Singh $\mathrm{M}$, et al. Redox activity of airborne particulate matter at different sites in the Los Angeles Basin. Environ Res. 2005;99(1):40-7. doi:10.1016/J.Envres.2005.01.003.

103. Li N, Sioutas C, Cho A, Schmitz D, Misra C, Sempf J, et al. Ultrafine particulate pollutants induce oxidative stress and mitochondrial damage. Environ Health Perspect. 2003;111(4):455-60. doi:10.1289/Ehp.6000.

104. Li QF, Wyatt A, Kamens RM. Oxidant generation and toxicity enhancement of aged-diesel exhaust. Atmos Environ. 2009;43(5):1037-42. doi:10.1016/J.Atmosenv.2008.11.018.

105. Koehler KA, Shapiro J, Sameenoi Y, Henry C, Volckens J. Laboratory evaluation of a microfluidic electrochemical sensor for aerosol oxidative load. Aerosol Sci Technol. 2014;48(5): 489-97. doi:10.1080/02786826.2014.891722.

106. Sameenoi Y, Koehler K, Shapiro J, Boonsong K, Sun YL, Collett $\mathrm{J}$, et al. Microfluidic electrochemical sensor for on-line monitoring of aerosol oxidative activity. J Am Chem Soc. 2012;134(25): 10562-8. doi:10.1021/Ja3031104.
107. Adams C, Riggs P, Volckens J. Development of a method for personal, spatiotemporal exposure assessment. J Environ Monitor. 2009;11(7):1331-9. doi:10.1039/B903841h.

108. Brook RD, Urch B, Dvonch JT, Bard RL, Speck M, Keeler G, et al. Insights into the mechanisms and mediators of the effects of air pollution exposure on blood pressure and vascular function in healthy humans. Hypertension. 2009;54(3):659-67. doi:10.1161/ Hypertensionaha.109.130237.

109. de Hartog JJ, Ayres JG, Karakatsani A, Analitis A, Brink H, Hameri $\mathrm{K}$, et al. Lung function and indicators of exposure to indoor and outdoor particulate matter among asthma and COPD patients. Occup Environ Med. 2010;67(1):2-10. doi:10.1136/ Oem.2008.040857.

110. Delfino RJ, Staimer N, Tjoa T, Gillen D, Kleinman MT, Sioutas C, et al. Personal and ambient air pollution exposures and lung function decrements in children with asthma. Environ Health Perspect. 2008;116(4):550-8.

111. Pelkonen AS, Nikander K, Turpeinen M. Reproducibility of home spirometry in children with newly diagnosed asthma. Pediatr Pulm. 2000;29(1):34-8. doi:10.1002/(Sici)1099-0496(200001) 29:1<34::Aid-Ppul6>3.0.Co;2-O.

112. Swan M. Sensor mania! The internet of things, wearable computing, objective metrics, and the quantified self 2.0. J Sens Actuator Networks. 2012;1(3):217-53. doi:10.3390/jsan1030217.

113. Ramachandran G, Adgate JL, Pratt GC, Sexton K. Characterizing indoor and outdoor 15 minute average PM2.5 concentrations in urban neighborhoods. Aerosol Sci Technol. 2003;37(1):33-45. doi:10.1080/02786820390112533.

114. Ramachandran G, Adgate JL, Hill N, Sexton K, Pratt GC, Bock D. Comparison of short-term variations (15-minute averages) in outdoor and indoor PM2.5 concentrations. J Air Waste Manag. 2000;50(7):1157-66.

115. Janes H, Sheppard L, Shepherd K. Statistical analysis of air pollution panel studies: an illustration. Ann Epidemiol. 2008;18(10): 792-802. doi:10.1016/J.Annepidem.2008.06.004.

116. Deklerk NH, English DR, Armstrong BK. A review of the effects of random measurement error on relative risk estimates in epidemiological-studies. Int J Epidemiol. 1989;18(3):705-12.

117. Samet JM. Some current challenges in research on air pollution and health. Salud Publ Mex. 2014;56(4):379-85. 